Research Article

Araştırma Makalesi

DOI: $10.24011 /$ barofd.538378
Bartın Orman Fakültesi Dergisi,

22(1): 123-132,

15 Nisan/April, 2020
Journal of Bartin Faculty of Forestry

p-ISSN :1302-0943

e-ISSN :1308-5875

\title{
Kızılçam Kabuğu ve Soğan Kabuğundan Elde Edilen Doğal Boyarmaddelerin Kağıt Hamurunu Boyama Performansı
}

\author{
Cengiz KEŞMER ${ }^{1,2^{*}}$, Ayhan GENÇER ${ }^{1}$, Ayben KILIÇ PEKGÖZLÜ ${ }^{1}$, Mehmet BEBEKLİ ${ }^{3}$ \\ ${ }^{1}$ Bartın Üniversitesi, Orman Fakültesi, Orman Endüstri Mühendisliği Bölümü,74100, BARTIN \\ ${ }^{2}$ Çukurova Üniversitesi, Aladağ Meslek Yüksekokulu, Ormancılık Bölümü,1000, ADANA \\ ${ }^{3}$ Çukurova Üniversitesi, Mühendislik Fakültesi, Tekstil Mühendisliği Bölümü,1000, ADANA
}

\section{Öz}

$\mathrm{Bu}$ çalışmada doğal boyarmadde kullanılarak kağıt hamuru boyanması hedeflenmiştir. Bu amaçla; ülkemizde yaklaşık 6 milyon hektar yayılış alanı ile ilk sırada yer alan Kızılçam (Pinus brutia) kabuğu ve Türk mutfağında önemli yeri olan soğan (Allium cepa) kabuğundan doğal boyarmadde elde edilme olanakları araştırılmıştır. Diğer taraftan, doğal boyarmaddelerin atık durumda olan lignoselülozik maddelerden elde edilmesi ile atıkların faydaya dönüştürülmesi de amaçlanmıştır. Elde edilen doğal boyar maddelerle, mordanlı ve mordansız olarak kağıt hamuru boyanmıştır. Mordan olarak Al(SO4)2.12H2O kullanılmıştır. Laboratuar ortamında elde edilen kağıtlara spektroskopik analizler yapılmıştır. Mordan ilaveli doğal boyalı kağıtların, mordansız doğal boyalı kağıtlara göre; hem görsel olarak hem de spektroskopik analiz verileri olarak daha iyi sonuçlar verdiği gözlenmiştir. Boyanmış kağıtların standart test sonuçlarına göre bu boyarmaddelerin kağıt hamurunun boyanmasında kullanılabileceği kanaatine varılmıştır.

Anahtar Kelimeler: Kızılçam kabuğu, soğan kabuğu, doğal boyarmadde, kağıt hamuru, spektroskopik analiz.

\section{The Paper Pulp Dyeing Performance of Natural Dyestuff Obtained From Red Pine Bark and Onion Skin}

\begin{abstract}
In this study, it is aimed to dye paper pulp using natural dyestuff. For this purpose; natural dyestuff production possibilities of red pine bark (Pinus brutia) having spread area of approximately 6 million hectares in Turkey and onion skin (Allium cepa) having an important role in the Turkish cuisine were investigated. On the other hand, it is also aimed to obtain natural dyestuffs from waste lingo-cellulosic materials and to convert wastes to be utilized. The resulting natural dyestuffs were prepared with mordant and mordant free. $\mathrm{Al}(\mathrm{SO} 4) 2.12 \mathrm{H} 2 \mathrm{O}$ was used as mordant. Spectroscopic analyzes were performed on the papers obtained in the laboratory. According to results, both visual and spectroscopic analysis data showed better results for natural dyed paper with mordant added compared to mordant free natural dyed papers. According to the standard test results of the dyed papers, it was concluded that both types of dyestuff could be used for dyeing the pulp.
\end{abstract}

Keywords: Red pine bark, onion skin, natural dyestuff, pulp, spectroscopic analysis. 


\section{Giriş}

Kağıt Endüstrisi, demir-çelik, tekstil, organik kimyasallar ve petrokimya endüstrileri gibi dünyanın en büyük ve en eski 5 endüstrisi içinde üçüncü sırayı almaktadır (Bostancı, 1987). Kâğıt, çizim, baskı veya ambalaj amacıyla kullanılan ince bir malzemedir. Genel olarak ağaç liflerinden elde edilen selüloz hamurunun preslenmesiyle oluşturulan levhaların kurutulması sonucunda elde edilir. Günümüzde kâğıt, basım ve ambalaj sektörünün en önemli malzemesidir. Teknolojik gelişmeler, reklam sektörünün gelişimi ve bunun sonucunda tüketici beklentilerinin artmasıyla kâğıttan da beklentiler artmıştır (Özcan ve Zelzele 2017). İlk zamanlar yazı ve baskı amaçlı kullanılan kağıt, zamanla insan yaşantısının temel ihtiyaç malzemesi haline gelmiştir. Genel kullanım amaçlı kağıtlar dışında özel kağıtlara da gereksinim duyulmaktadır. Özel kağıtların kullanım yerine bağlı olarak değişik özellik ve renklerde olması istenmektedir. Renklendirme işlemi için boyama yapılmaktadır. Boyama işleminde sentetik ve doğal boyalar kullanılmaktadır. Son yıllarda artan, insan sağlığı ve çevre bilinci nedenleri ile doğal boyalar daha fazla tercih edilmektedir. Ayrıca, doğal boyalar tekstil, odun, vernik, deri, mürekkep, yiyecek, kozmetik ve eczacılık endüstrileri gibi farklı alanlarda da kullanılan maddelerdir (Krishnamurty ve ark., 2002).

Anadolu'nun zengin bitki örtüsü Orta Asya Türk boylarından, Osmanlı İmparatorluğu'na ve günümüze kadar el dokumacılığımızda doğal boyarmadde kaynağı olmuştur. Bu özelliği ile sentetik boyarmaddelerin kullanımına kadar (1856 yılına kadar) en kaliteli ve çok doğal boya ihraç eden coğrafyadır (Korur, 1937; Bebekli, 1998). Her ne kadar sentetik boyaların kullanımı doğal boya ihracatını düşürse de Türkiye doğal boyama ve doğal boyamada kullanılan bitkiler açısından zengin bir potansiyele sahip olmasından dolayı oldukça eski tarihi bir geleneğe sahiptir (Özgür ve ark., 1956).

Doğal boyalar, sentetik boyalara göre vücudun organizmasına uygun, nazik, yumuşak, ince ve huzurlu bir etki oluştururlar (Krishnamurty ve ark., 2002). Dolayısıyla, doğal boyalar sentetik boyalara alternatif (Onal, 1996; Luciana ve ark., 1997; Kamel ve ark., 2005; Calogero ve ark., 2008 ) çevreyle uyumlu, zehirsiz, insan vücudunda alerjen ve kanserojen etki göstermeme özelliklerinin yanı sıra kolaylıkla elde edilebilirler ve yenilenebilirler (Onal, 1996; Saha ve ark., 2007; Adeel ve ark., 2009). Bu nedenlerle ucuz üretilen sentetik boyalarla dünya pazarında rekabet edebilmektedirler (Dixit ve ark., 2005; Öğütgen, 2008 ).

Kağıt hamuruna doğal boya ilavesi ile ilgili tarihi belgeler mevcut olmasına rağmen, kullanılan hammadde ve yöntemlerle ilgili yazılı çalışmalar maalesef günümüze kadar ulaşamamıştır. Bunun tek nedeni kağıt üretimi reçetelerinin özellikle de doğal boya reçetelerinin gizli tutulmasıdır. Çünkü, 19. Yüzyılın ikinci yarısına kadar kitapların yazımında ve kağıtların renklendirilmesinde sadece doğal boyalar kullanılmıştır.

Yapılan bir çalışmada, nar, nar kabuğu, kına, soğan kabuğu ve gül yaprağından doğal boyarmadde elde edilmiştir. $\mathrm{Bu}$ boyarmadde ile boyama işleminde kağıt örnekleri mordanlı (şap=, $\mathrm{KAl}\left(\mathrm{SO}_{4}\right)_{2} .12 \mathrm{H}_{2} \mathrm{O}$ ) boya içerisine daldırmak suretiyle boyanmıştır. Boyanmış kağıt örnekleri suni yaşlandırmaya tabi tutulduğunda en iyi renk stabilitesini kına ile boyanmış kağıtlar gösterirken en az renk stabilitesini ise nardan elde edilmiş doğal boya ile boyanmış kağıtlar göstermiştir (Çakar, 2012).

$\mathrm{Bu}$ çalışmada, kağıt hamuruna doğal boya ilavesi ile kağıt üretimi yapılmış ve doğal boyanın kağıt hamuruna tutundurulması amaçlanmıştır. Doğal boya eldesinde; kızılçam (Pinus brutia) kabuğu ve soğan (Allium cepa) kabuğu kullanılmıştır. Böylece, atık durumda olan lignoselülozik maddelerden doğal boyarmaddeler elde edilerek atıkların faydaya dönüştürülmesi sağlanacaktır.

\section{Materyal ve Metot}

\subsection{Materyal}

Bu çalışmada kullanılan kağıt hamuru Türkiye'de temizlik kağıdı üreten özel firmadan temin edilmiştir. Özel bir işletmeden temin edilen kağıt hamurunun bazı kimyasal ve morfolojik özellikleri Tablo 1 'de verilmiştir. 
Tablo 1. Eucalyptus grandis'den elde edilmiş kağıt hamurunun bazı kimyasal ve morfolojik özellikleri

\begin{tabular}{c|c|c}
\hline Kullanılan kağıt hamurunun bazı özellikleri & Kullanılan standart & Ortalama \\
\hline Parlaklık, \%ISO & ISO - 2469/2470/3688 & 0.17 \\
\hline Kül, \% & ISO - 1762 & 0.35 \\
\hline Lifler, milyon/g & Morphi & 22.9 \\
\hline Ortalama Lif Uzunluğu, mm & Morphi & 0.67 \\
\hline Kabalık, mg/100m & Morphi & 6.45 \\
\hline Lif genişliği, $\mu \mathrm{m}$ & Morphi & 15.7 \\
\hline
\end{tabular}

Doğal boya üretimi yapılan Kızılçam(Pinus brutia) kabuğu Adana ili Aladağ sınırları içerisinde yer alan Pos orman işletme sınırları içerisinde kesimlerden arta kalan kabuklardan elde edilmiştir. Soğan kabuğu ise Adana ili Sarıçam ilçesindeki halk pazarlarından toplanmıştır. Doğal boya yapımında kullanılan öğütülmüş kızılçam kabuğu ve soğan kabuğu görselleri aşağıda Şekil 2'de verilmiştir.

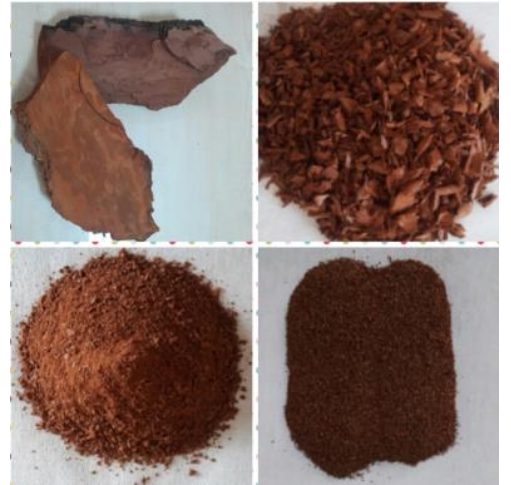

$-\mathrm{A}-$

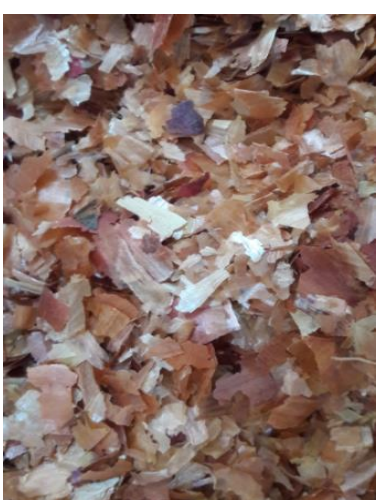

$-\mathrm{B}-$

Şekil 2. Öğütülmüş kızılçam kabuğu (A) ve öğütülmüş soğan kabuğu (B)

\subsection{Metot}

\subsubsection{Boyar Madde Hazırlama}

Öğütülmüş 150 g'lık kızılçam ve soğan kabukları ayrı ayrı 1500 ml'lik destile su ile birlikte önce $120^{\circ} \mathrm{C}$ 'de 15 dakika hafif kaynatıldıktan sonra 4 saat boyunca $80^{\circ} \mathrm{C}$ 'de ara ara karıştırılarak etüv içerisinde bekletilmiştir. Süre sonunda etüvden alınarak soğumaya bırakılmış ve sırasıyla 50 ve 100 mesh'lik eleklerden süzülmüştür.

\subsubsection{Kullanılacak Kağıt Hamurunun Liflendirilmesi}

Çalışmada Eucalyptus grandis'den elde edilmiş kağıt hamuru kullanılmıştır. Rutubet tayini yapıldıktan sonra $240 \mathrm{~g}$ tam kuru hamur alınarak 8 lt su içerisinde 1 gün bekletilmiştir. Daha sonra mikserde açma işlemi yapılmıştır.

\subsubsection{Kağıt Yapımı}

Kağıt yapımı için laboratuvar tipi Rapid Köthen marka kağıt makinesi kullanılmıştır. Boyasız (şahit) ve boyalı, boyalı + mordanl $\left(\mathrm{Al}\left(\mathrm{SO}_{4}\right)_{2} \cdot 12 \mathrm{H}_{2} \mathrm{O}\right)$ olmak üzere üç farklı özellikte kağıt üretilmiştir. Kağıt üretiminden önce soğan kabuğu ve kızılçam kabuğundan elde edilen boyarmaddeler ayrı ayrı kağıt hamuru süspansiyonuna ilave edilmiş ve belirli aralıklarla karıştırılmıştır. Mordan hazırlanmasında 1gr şap alınarak 500ml saf su içinde karıştırılarak çözünmesi sağlamıştır. Doğal boya+kağıt hamuru karışımı 1 gün bekledikten sonra 50 ml mordan süspansionu ilave edilmiş ve 1 saat beklenmiştir, bu bekleme esnasında ara sıra karıştırılmıştır. Her üç hamurdan ayrı ayrı olmak üzere 15 adet deneme kağıdı yapılmıştır. 


\subsubsection{Spektrofotometre Analiz Sonuçlarının Belirlenmesi}

Spektrofotometre analizleri Çukurova Üniversitesi Mühendislik Mimarlık Fakültesi Tekstil Mühendisliği Bölümü Gözlem ve Görüntüleme Laboratuarında MINOLTA (Spectrophotometer CM - 3600d, D65) marka spectrometre ile Real Color Spectal Renk Ölçümü v1.3 (2006) programı kullanılarak yapılmıştır. Laboratuar ortamında üretilen ve spektroskopik analizlere tabi tutulan kağıtların mordan ve boyarmadde içerikleri Tablo 2’de verilmiştir.

Tablo 2. Spektroskopik analizlere tabi tutulan numuneler

\begin{tabular}{c|l|c|c}
\hline No & \multicolumn{1}{|c|}{ Numune } & Boyarmadde & Mordan (Şap) \\
\hline 1 & Şahid & - & - \\
\hline 2 & Soğan Kabuğu & $150 \mathrm{ml}$ & - \\
\hline 3 & Soğan Kabuğu & $150 \mathrm{ml}$ & - \\
\hline 4 & Kızılçam Kabuğu & $150 \mathrm{ml}$ & - \\
\hline 5 & Kızılçam Kabuğu & $150 \mathrm{ml}$ & - \\
\hline 6 & Kızılçam Kabuğu & $150 \mathrm{ml}$ & $50 \mathrm{ml}$ \\
\hline 7 & Soğan Kabuğu & $150 \mathrm{ml}$ & $50 \mathrm{ml}$ \\
\hline 8 & Soğan Kabuğu & $150 \mathrm{ml}$ & $50 \mathrm{ml}$ \\
\hline 9 & Soğan Kabuğu & $150 \mathrm{ml}$ & $50 \mathrm{ml}$ \\
\hline 10 & Soğan Kabuğu & $150 \mathrm{ml}$ & $50 \mathrm{ml}$ \\
\hline 11 & Kızılçam Kabuğu & $150 \mathrm{ml}$ & $50 \mathrm{ml}$ \\
\hline 12 & Kızılçam Kabuğu & $150 \mathrm{ml}$ & $50 \mathrm{ml}$ \\
\hline 13 & Kızlçam Kabuğu & $150 \mathrm{ml}$ & $50 \mathrm{ml}$ \\
\hline 14 & Kızılçam Kabuğu & $150 \mathrm{ml}$ & $50 \mathrm{ml}$ \\
\hline 15 & Kızılçam Kabuğu & $150 \mathrm{ml}$ &
\end{tabular}

Rengin daha kolaylıkla anlaşılabilir bir tanımını yapmak üzere 1976 yılında CIE, X, Y ve Z tristimulus değerlerinden hesaplanan $L^{*}, a^{*}$ ve $b^{*}$ şeklindeki üç koordinatı bulunan ve CIELab sistemi olarak adlandırılan bir sistemi tanımlamıştır (Şekil 1). X, Y ve Z tristimulus değerleri, rengi sayısal olarak ifade edebilmekle birlikte renk hakkında bilgi vermemektedir (Acar, 2009).

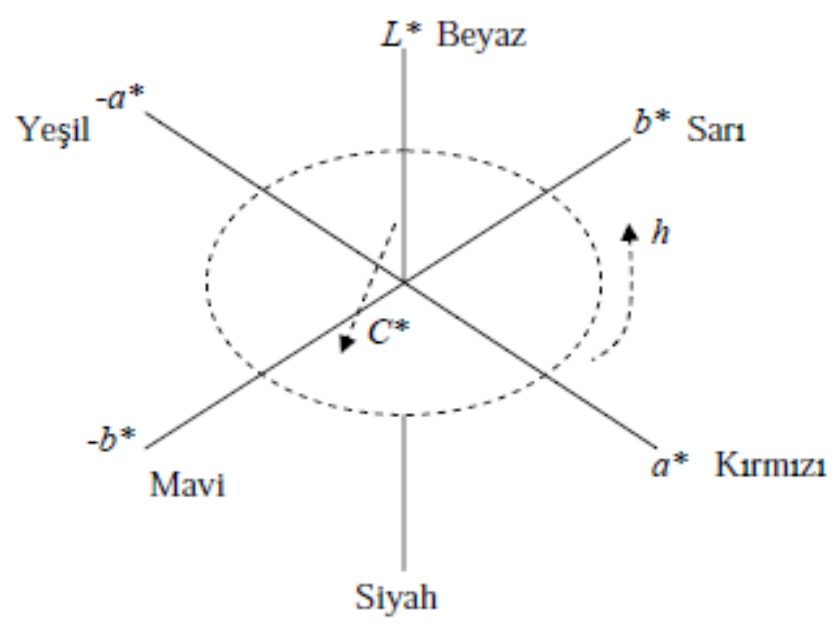

Şekil 1 CIELab renk uzayı (Acar, 2009)

CIE L*a*b* renk uzayında $L^{*} ; 0$ ila 100 arasında bir değer alır. $L^{*}=100$ değeri beyaz rengi, $L^{*}=0$ değeri ise siyah rengi gösterir. $a^{*}$ ve $b^{*}$ ifadeleri ise kromatik karakteristiklerdir. a* eksiden artıya doğru yeşilden kırmızıya giderken, $b^{*}$ eksiden artıya doğru maviden sarıya gider. $C^{*}$ ise; renk doygunluğunu, $\mathrm{h}$ ise ton açısını ifade 
etmektedir (Appolonia ve ark., 2006). $\mathrm{a}^{*}$ ve $\mathrm{b}^{*}$ eksenleri birbirlerine $90^{\circ} \mathrm{C}$ 'lik açı yapar ve nötral noktada kesişir (parlaklığa göre beyaz veya gri ). Üçüncü eksen L*, koyuluğun- açıklığın (parlaklığın) bir ölçüsüdür. Aynı rengin farklı tonları, $a^{*}$ ve $b^{*}$ eksenleri tarafindan oluşturulan düzlem içerisinde nötral noktadan dışarıya doğru uzanan bir çizgi üzerinde yer alır. Kırmızıdan sarıya doğru artış gösteren dönme açısı " $h$ " (derece cinsinden), rengin bir ölçüsüdür. Örneğin $h=90^{\circ}$ sarı bir renk tonunu, $h=0^{\circ}$ kırmızı bir renk tonunu ve $h=270^{\circ}$ mavi bir renk tonunu ifade etmektedir. Nötral noktadan uzaktaki bir nokta, kromayı $\left(\mathrm{C}^{*}\right)$ ifade eder ve bu da belirli bir parlaklığa sahip (L* değerindeki) bir rengin doygunluğunun(canlılığının) bir ölçüsüdür. Herhangi bir renk, ya $\mathrm{L}^{*}, \mathrm{a}^{*}, \mathrm{~b}^{*}$ koordinatları ile ya da $\mathrm{L}^{*}, \mathrm{C}^{*}$, h değerleriyle belirlenebilmektedir. Genel olarak rengin, koloristik açıdan düşünüldüğünde $a^{*}$ ve $b^{*}$ koordinatları yoluyla ifade edilmesinden çok renk açısı olan $h$ ve kroma $C^{*}$ 'nin kullanımıyla tanımlanması daha uygundur. Her iki durumda da $\mathrm{L}^{*}$, rengin koyuluğunun-açıklığının (parlaklığının) bir ölçüsünü göstermektedir. L*'nin değerleri, siyah renk için 0 ile beyaz renk için 100 değeri arasında değerler almaktadır. $a^{*}$ ve $b^{*}$ 'nin çok parlak renkler için en yüksek değerleri, yaklaşık olarak +80 ve 80 arasında değerler almaktadır(Acar, 2009). Nötral nokta (yani $a^{*}=b^{*}=0$ ) etrafinda çizilen bir çember sabit kromaya sahip bir renk çemberini tanımlarken ve kırmızıdan başlamak üzere $\mathrm{h}$ açısı (derece cinsinden) rengin bir ölçüsünü ifade etmektedir (Hunterlab, 1995). Kromatik renk uzayı tanımlandığında farklı iki rengin aralarındaki farkı ölçmek gayet kolaydır. Renklendirilmiş iki yüzeyin renk farkı iki nokta arasındaki geometrik uzaklıktır ve CIE L*a*b*renk uzayında aşağıdaki 1 no’lu denklem ile hesaplanır ( Çakar, 2011).

$$
\begin{aligned}
& \Delta E=\sqrt{\left(\Delta L^{*}\right)^{2}+\left(\Delta a^{*}\right)^{2}+\left(\Delta b^{*}\right)^{2}} \\
& \Delta \mathrm{L}^{*}=\mathrm{L} 2 *-\mathrm{L} 1 \\
& \Delta \mathrm{a}^{*}=\mathrm{a} 2 *-\mathrm{a} 1 * \\
& \Delta \mathrm{b}^{*}=\mathrm{b} 2 *-\mathrm{b} 1 *
\end{aligned}
$$

Renk farklılıklarının $\Delta \mathrm{L}^{*}, \Delta \mathrm{a}^{*}$ ve $\Delta \mathrm{b}^{*}$ şeklinde üç bileşene ayrılmasına rağmen, öncelikle bunlardan birincisi önemlidir ve $L^{*}$ numune - L*standart ișleminin değerinin pozitif olmasl numunenin standarttan daha açık olduğunu, negatif olması ise daha koyu olduğunu göstermektedir (Öner, 2007). $\Delta \mathrm{C}^{*}$ (C*numune - $\mathrm{C}^{*}$ standart), değeri hesaplandığında $\Delta C^{*}$ 'nin pozitif olması, numunenin daha yüksek bir kromaya (doygunluğa) sahip olduğunun, negatif olması ise numunenin daha düşük bir kromaya (doygunluğa) sahip olduğunun göstergesidir.

\section{Bulgular ve Tartışma}

$\mathrm{Bu}$ çalışmada toplam 15 adet kağıt üretilmiştir. Şahid ve doğal boyalı kağıtların spektroskopik analizler sonucunda elde edilen L, a, b, C ve h değerleri Tablo 3'te verilmiştir.

Tablo 3. Doğal boyalı kağıtların L, a, parlaklık, C(doygunluk) ve h(derece cinsinden) değerleri

\begin{tabular}{c|c|c|c|c|c|c}
\hline Kağıt No & $\mathbf{L}$ & $\mathbf{a}$ & $\mathbf{b}$ & Parlaklık & $\mathbf{C}$ (Doygunluk) & $\mathbf{h}$ \\
\hline 1 & 91.67 & 12.96 & 0.78 & 79.12 & 0.823 & 109.16 \\
\hline 2 & 73.52 & 12.08 & 24.24 & 31.59 & 22.965 & 62.21 \\
\hline 3 & 70.35 & 12.76 & 24.51 & 26.93 & 24.457 & 63.79 \\
\hline 4 & 81.5 & 12.21 & 24.39 & 46.86 & 14.494 & 67.22 \\
\hline 5 & 78.53 & 12.88 & 23.57 & 40.72 & 17.157 & 63.05 \\
\hline 6 & 77.7 & 10.71 & 23,77 & 38.77 & 18.237 & 62.91 \\
\hline 7 & 71.61 & 10.8 & 21.94 & 22.26 & 32.182 & 74.71 \\
\hline 8 & 71.53 & 5.61 & 13.36 & 18.26 & 33.028 & 75.54 \\
\hline 9 & 73.02 & 7.78 & 15.29 & 22.62 & 33.715 & 76.71 \\
\hline 10 & 72.19 & 8.3 & 16.24 & 22.47 & 32.674 & 75.57 \\
\hline 11 & 62.63 & 8.49 & 31.04 & 17.55 & 27.487 & 61.87 \\
\hline 12 & 63.56 & 8.25 & 31.98 & 18.17 & 27.332 & 63.76 \\
\hline 13 & 63.04 & 7.75 & 32.81 & 17.81 & 27.525 & 62.38 \\
\hline 14 & 65.04 & 8.14 & 31.64 & 19.9 & 26.54 & 62.61 \\
\hline 15 & 63.25 & -0.27 & 20.32 & 21.62 & 27.041 & 61.55 \\
\hline
\end{tabular}


L, a ve b değerleri rengin tonu (açı/koyu) ile ilgilidir. Tablo 3 incelendiğinde doğal boyalı kağıtların beklendiği gibi şahit numuneye göre daha koyu olduğu tespit edilmiştir. En koyu kağıtlar mordan ilave edilmiş kızılçam kabuğu boyalı kağıtlardan (62.63) edilmiştir. En açık renk ise mordansız soğan kabuğu ile boyanmış kağıtta (81.5) elde edilmiştir. Doğal boya ilavesi rengi \%11 ile \%32 arasında daha koyu bir renk olmasını sağlamıştır.

h (renk açısı) değerleri incelendiğinde, kırmızı-sarı aralığında olduğu ve daha fazla sarı renge yakın olduğu gözükmektedir. CIELab renk uzayında 0; kırmızı renk 90 ise; sarı renk anlamına gelmektedir. Boyalı kağıtların h değerleri ise 61.55 ile 76.71 arasında tespit edilmiştir. Sarıya en yakın renk mordanlı soğan kabuğu ile boyanmış kağıtlardan elde edilmiştir ve ortalama değeri ise 75.63 olarak bulunmuştur.

$\mathrm{C}$ (doygunluk/renk canlılığı) değerlerinin ise şahit numunesinde ortalama $0.82 \mathrm{iken;} \mathrm{boyalı} \mathrm{kağıtlarda} \mathrm{en} \mathrm{düşük} \mathrm{C}$ değeri 4 No'lu kızılçam kabuğu boyalı ve mordansız numune (14.49) tespit edilmiştir. En yüksek C değeri ise 9 No'lu mordan ilaveli soğan kabuğu ile boyanmış numunede elde edilmiştir (33.71)'dir. Mordanlı kağıtların, mordansız kağıtlara oranla $\mathrm{C}$ değerlerinin daha yüksek olduğu gözlenmiştir. Mordan ilavesi ile soğan kabuğu boyalı kağıtların $\mathrm{C}$ değerleri ortalama \%39 artarken, bu oran kızılçam kabuğu boyalı kağıtlarda \%63 oranında gerçekleşmiştir.

Parlaklık değeri sonuçlarına bakıldığında (Tablo 3) şahit numunenin doğal boyalı kağıtlardan daha parlak olduğu görülmektedir. Boyalı kağıtlarda en yüksek parlaklık değeri 46.86 ile mordan ilave edilmemiş kızılçam kabuğu boyalı kağıtta elde edilmiştir, en düşük parlaklık değeri ise 17.55 ile mordan ilave edilmiş kızılçam kabuğu boyalı kağıtta elde edilmiştir. Mordan ilave edilmeyen kızılçam kabuğu ve soğan kabuğu ile boyanmış kağıtların parlaklık değerleri incelendiğinde; kızılçam kabuğu ile boyanmış kağıtların parlaklık değerlerinin yüksek olduğu gözlenmiştir. Mordan ilavesi ile; tam tersine soğan kabuğu boyası ile boyanmış kağıtların parlaklıklarının kızılçam kabuğu ile boyanmış kağıtlardan daha yüksek olduğu gözlenmiştir. Genel olarak baktığımızda doğal boya ilavesinin önemli miktarda parlaklığg düşürdüğü belirlenmiştir.

Şahid ve doğal boyalı kağıtların $\Delta \mathrm{a}, \Delta \mathrm{b}, \Delta \mathrm{L}, \Delta \mathrm{E}$ ve $\Delta \mathrm{C}$ sonuçları değerlendirildiğinde (Tablo 4), soğan kabuğu boyalı mordanlı kağıtların mordansız soğan kabuğu boyalı kağıtlara göre daha koyu daha yeşil, daha sarı ve daha kuvvetli olduğu tespit edilmiştir. Kızılçam kabuğu boyalı mordanlı kağıtların mordansız kızılçam kabuğu boyalı kağıtlara göre ise daha koyu, daha kırmızı, daha sarı ve daha kuvvetli olduğu tespit edilmiştir. Tablo 4'de $\Delta \mathrm{C}$ değerleri incelendiğinde sonuçların pozitif değerlikli olduğu görülmektedir. Bu sonuçlar mordan ilavesi ile rengin daha yüksek doygunluğa ve dolayısıyla daha yüksek canlılığa ulaştığı anlamına gelmektedir.

Tablo 4. Doğal boyalı kağıtların $\Delta \mathbf{a}, \Delta \mathbf{b}, \Delta \mathbf{L}, \Delta \mathbf{E}$ ve $\Delta \mathbf{C}$ değerleri

\begin{tabular}{l|c|c|c|c|c}
\hline Karşılaştırılan Kağıtlar & $\Delta \mathbf{a}$ & $\Delta \mathbf{b}$ & $\Delta \mathbf{L}$ & $\Delta \mathbf{E}$ & $\Delta \mathbf{C}$ \\
\hline 1 ve 2 & 10.977 & 19.539 & -18.147 & 28.84 & 22.142 \\
\hline 1 ve 3 & 11.073 & 21.165 & -21.317 & 32.02 & 23.634 \\
\hline 1 ve 4 & 5.891 & 12.586 & -10.166 & 17.21 & 13.671 \\
\hline 1 ve 5 & 8.045 & 14.516 & -13.14 & 21.17 & 16.334 \\
\hline 1 ve 6 & 8.575 & 15.459 & -13.966 & 22.53 & 17.414 \\
\hline 1 ve 7 & 8.757 & 30.266 & -20.057 & 37.35 & 31.36 \\
\hline 1 ve 8 & 8.517 & 31.204 & -20.138 & 38.1 & 32.205 \\
\hline 1 ve 9 & 8.018 & 32.035 & -18.646 & 37.92 & 32.892 \\
\hline 1 ve 10 & 8.413 & 30.866 & -19.48 & 37.46 & 31.852 \\
\hline 1 ve 11 & 13.23 & 23.462 & -29.032 & 39.6 & 26.664 \\
\hline 1 ve 12 & 12.355 & 23.738 & -28.107 & 38.81 & 26.509 \\
\hline 1 ve 13 & 13.032 & 23.611 & -28.629 & 39.33 & 26.703 \\
\hline 1 ve 14 & 12.478 & 22.788 & -26.629 & 37.2 & 25.717 \\
\hline 1 ve 15 & 13.154 & 22.998 & -28.412 & 38.85 & 26.219 \\
\hline 2 ve 7 & -2.22 & 10.727 & -1.909 & 11.12 & 9.217 \\
\hline 2 ve 8 & -2.46 & 11.665 & -1.991 & 12.09 & 10.063 \\
\hline 2 ve 9 & -2.959 & 12.496 & -0.499 & 12.85 & 10.75 \\
\hline 2 ve 10 & -2.564 & 11.327 & -1.333 & 11.69 & 9.709 \\
\hline 4 ve 11 & 7.349 & 10.876 & -18.866 & 22.98 & 12.993 \\
\hline 4 ve 12 & 6.474 & 11.151 & -17.941 & 22.09 & 12.838 \\
\hline 4 ve 13 & 7.151 & 11.024 & -18.463 & 22.66 & 13.032 \\
\hline 4 ve 14 & 6.597 & 10.202 & -16.463 & 20.46 & 12.046 \\
\hline 4 ve 15 & 6.467 & 10.978 & -16.562 & 22.17 & 12.467 \\
\hline 5 ve 11 & 5.185 & 8.496 & -15.892 & 18.96 & 10.33 \\
\hline 5 ve 12 & 4.309 & 9.221 & -14.967 & 18.1 & 10.175 \\
\hline
\end{tabular}




\begin{tabular}{l|c|c|c|c|c}
\hline 5 ve 13 & 4.987 & 9.094 & -15.489 & 18.64 & 10.369 \\
\hline 5 ve 14 & 4.433 & 8.272 & -13.489 & 16.43 & 9.383 \\
\hline 5 ve 15 & 5.109 & 8.481 & -15.272 & 18.2 & 9.885 \\
\hline 6 ve 11 & 4.655 & 8.003 & -15.067 & 17.68 & 9.25 \\
\hline 6 ve 12 & 3.78 & 8.278 & -14.142 & 16.82 & 9.095 \\
\hline 6 ve 13 & 4.458 & 8.151 & -14.663 & 17.36 & 9.288 \\
\hline 6 ve 14 & 3.903 & 7.329 & -12.663 & 15.14 & 8.303 \\
\hline 6 ve 15 & 4.579 & 7.538 & -14.447 & 16.93 & 8.804 \\
\hline
\end{tabular}

Malzemelerdeki görünümü ve renk biçimlenmesini etkili olan üç parametre saçılma, absorbsiyon, ve yansımadır. Tekstil ürünleri gibi opak numunelerde yüzeyin 1şığ saçma özelliği ve 1şığı absorblama ile bu yüzeyin üzerine düşen ışı̆̆ı yansıtması arasındaki ilişki Kubelka-Munk denklemi ile açıklanır (Akgün ve ark. 2012-Kubelka, 1948-Mc Donald, 1987-Mc Laren, 1986). Aşağıdaki eşitlik 2'de Kubelka-Munk denklemi verilmiştir.

$$
K / S=(1-R) 2 / 2 R
$$

Bu eşitlikte, $K$; absorbsiyon katsayısını, $S$; nesenenin ışı̆̆ı saçma katsayısı olan saçılma katsayısını ve $R$; kumaş yansımasını ifade etmektedir. $K / S$ değeri bir nesnenin renk kuvveti (renkliliği) olarak tanımlanmaktadır (Akgün ve ark., 2012- Mc Donald, 1987-Tilley, 2000).

\section{K/S Ifade Sekilleri:}

- Rengin iç yüzü

- Renk kuvveti

- Renklilik değeri

- Rengin gücü

- Boyama kuvveti

Tablo 5 incelendiğinde, K/S verimi mordanlı ve mordansız kağıtlarda farklılıklar göstermiştir. Mordansız kağıtlara baktığımızda soğan kabuğu boyalı kağıtların $\mathrm{K} / \mathrm{S}$ değerlerinin kızılçam kabuğu boyalı kağıtların $\mathrm{K} / \mathrm{S}$ değerlerinden yaklaşık 5.2 kat daha iyi olduğu görülmüştür. Mordan ilavesi ile soğan kabuğu boyalı kağıtların $\mathrm{K} / \mathrm{S}$ verimi yaklaşı $\% 21$ oranında düşerken, kızılçam kabuğu boyalı kağıtlarda ise yaklaşık \%29 oranında artış göstermiştir.

Soğan kabuğu boyalı ve mordansız kağıtların K/S değerleri mordanlı ve soğan kabuğu boyalı kağıtlara göre daha yüksektir. Kızılçam kabuğu boyalı ve mordansız kağıtların K/S değerleri mordanlı ve kızılçam kabuğu boyalı kağıtlara göre daha düşüktür. Soğan kabuğu boyalı ve mordansız kağıtların K/S değerleri, kızılçam kabuğu boyalı ve mordansız kağıtların K/S değerlerinden daha yüksektir. Soğan kabuğu boyalı ve mordansız kağıtların $\mathrm{K} / \mathrm{S}$ değerleri boya miktarı arttıkça artmaktadır. Kızılçam kabuğu boyalı ve mordansız kağıtların $\mathrm{K} / \mathrm{S}$ değerleri boya miktarı arttıkça artmaktadır. Soğan kabuğu boyalı ve mordanlı kağıtların $\mathrm{K} / \mathrm{S}$ değerleri mordan miktarı arttıkça artmaktadır.

Tablo 5. Doğal boyalı kağıtların K/S değerleri

\begin{tabular}{|c|c|c|c|c|c|c|c|c|c|c|c|c|c|c|c|}
\cline { 2 - 14 } \multicolumn{1}{c|}{} & 1 & 2 & 3 & 4 & 5 & 6 & 7 & 8 & 9 & 10 & 11 & 12 & 13 & 14 & 15 \\
\hline $\mathbf{K} / \mathbf{S}(\mathbf{D}: \mathbf{B}(\mathbf{n} / \mathbf{m})=\mathbf{4 0 0}$ & 0.04 & 2.2 & 2.72 & 0.47 & 0.63 & 0.73 & 1.97 & 2 & 1.9 & 1.92 & 2.7 & 2.53 & 2.63 & 2.21 & 2.5 \\
\hline
\end{tabular}

Laboratuvar ortamında elde olunan kağıtların renk tonları Şekil 3 'te verilmiştir. 


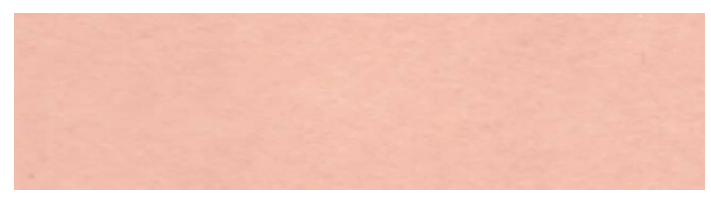

2: Soğan Kabuğu $+150 \mathrm{ml}+$ Mordansız $+2.967 \mathrm{gr}$

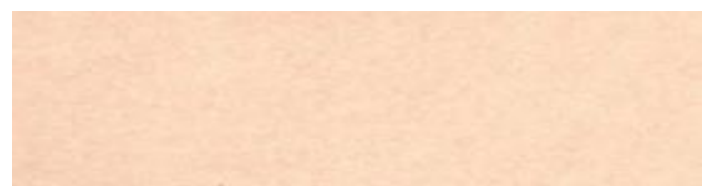

4: Kızılçam Kabuğu + 150ml + Mordansız + 2.700gr

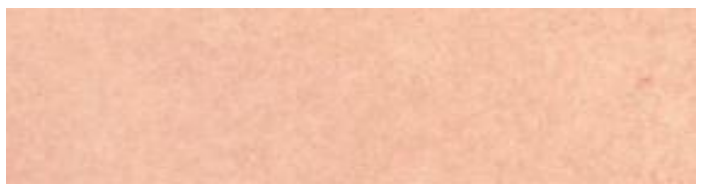

6: Kızılçam Kabuğu $+150 \mathrm{ml}+$ Mordansız $+2.515 \mathrm{gr}$

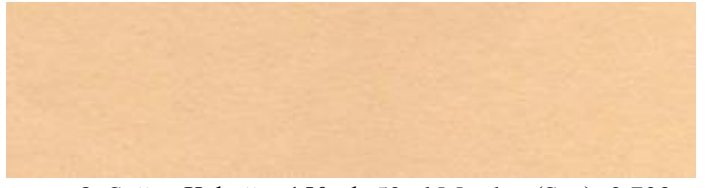

8: Soğan Kabuğu+150ml+50ml Mordan (Şap)+2.703gr

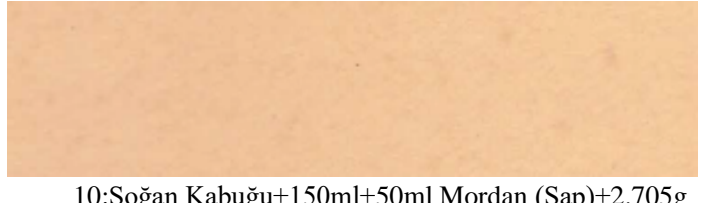

10:Soğan Kabuğu+150ml+50ml Mordan (Sap)+2.705g

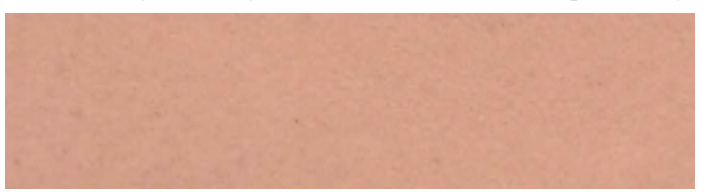

12: Kızılçam Kabuğu + 150ml + 50ml Mordan(Şap) $+2.596 \mathrm{~g}$

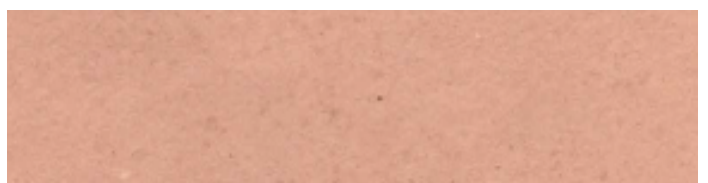

14: Kızılçam Kabuğu + 150ml + 50ml Mordan(Şap) + 2.794gr

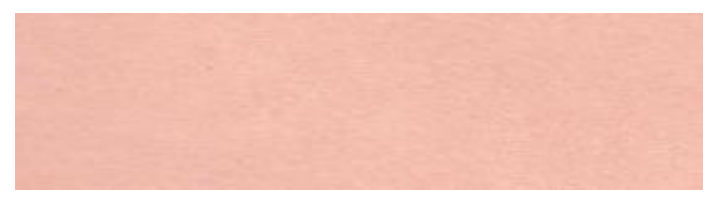

3: Soğan Kabuğu $+150 \mathrm{ml}+$ Mordansız $+2.295 \mathrm{gr}$

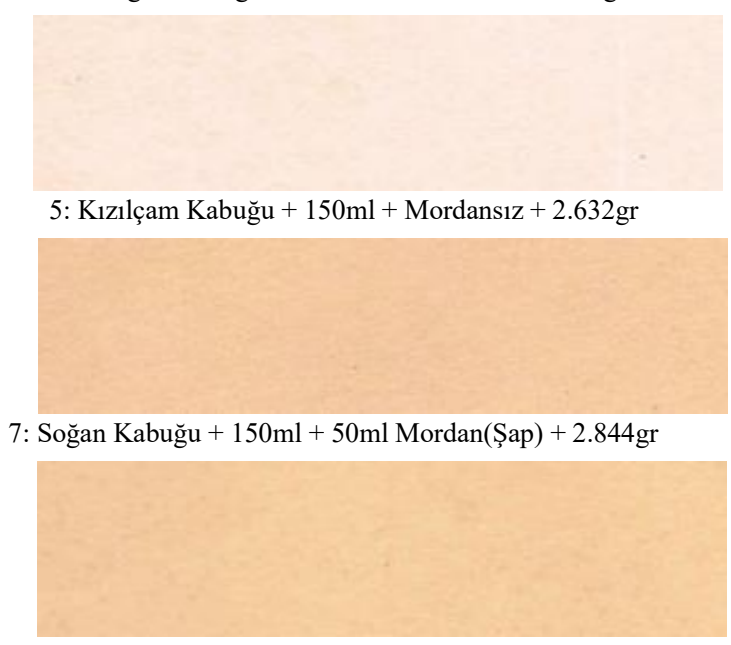

9: Soğan Kabuğu+150ml+50ml Mordan(Şap)+2.777gr

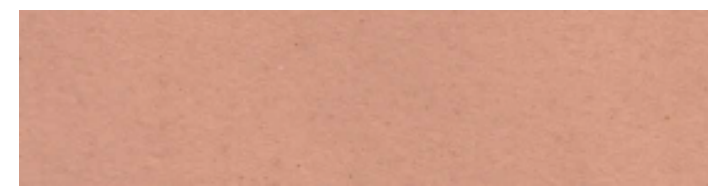

11:Kızılçam Kabuğu+150ml+50ml Mordan(Şap)+2.587gr

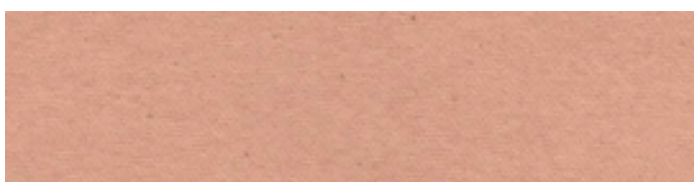

13: Kızılçam Kabuğu $+150 \mathrm{ml}+50 \mathrm{ml}$ Mordan(Şap $)+2.601$ gr

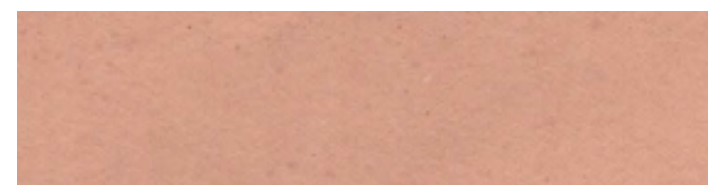

15: Kızılçam Kabuğu + 150ml + 50ml Mordan(Şap) + 2.528gr

Şekil 3. Doğal boyalı kağıtlarda elde edilen renk tonları.

\section{Sonuç ve Öneriler}

Sonuç olarak; kaynatma yöntemiyle soğan kabuğu ve kızılçam kabuğundan elde edilen doğal boyarmaddelerin hem mordansız hem de mordan kullanılarak kağıt hamuruna tutundurulması sağlanmıştır. Bağlayıcı ajan olarak mordan ilavesinin soğan kabuğu ve kızılçamdan elde edilen boyarmaddenin daha iyi bağladığı tespit edilmiştir. Mordan ilavesi ile özellikle kızılçam kabuğundan elde edilen doğal boyarmadde ile mordansız olan numuneye oranla yaklaşık \%29 daha fazla tutunum sağlanmıştır. Soğan kabuğu ve kızılçam kabuğu gibi doğal atıkların faydaya dönüştürülebilir olduğu görülmüştür. Her ne kadar soğan kabuğu satışı konusunda bir bulgu elde edilememiş (Yaman, 2012) ise de, değerlendirilmesi durumunda ekonomik değeri olabilir. Benzer şekilde Kızılçam kabuğu da ormanlarda atık olarak bırakılmaktadır. Orman genel müdürlüğü 2016 yılı içerisinde $5.949 .506 \mathrm{~m}^{3}$ kabuksuz kızılçam odun üretimi gerçekleştirmiştir. Bu bilgiden hareketle kızılçam kabuğu üzerinde yapılan bir çalışmadan (Koparan, 2015) yola çıkarak yaklaşık $800.000 \mathrm{~m}^{3}$ kızılçam kabuğu ormanlarda çürümeye bırakılmaktadır. Değerlendirilmesi durumunda önemli bir biyo kütledir. 


\section{Teşekkür}

Bu çalışma, Bartın Üniversitesi BAP Koordinatörlüğü tarafından "2018-FEN-A-002" kodlu "Lignoselülozik Hammaddelerden Elde Edilen Doğal Boyarmaddelerin Kağıda Tutundurulmasında Nişastanın Kullanımı" adlı projeden yapılmıştır. Katkılarından dolayı Bartın Üniversitesine teşekkür ederiz.

\section{Kaynaklar}

1. Acar, K. (2009). Fluoresans Renkler İçeren Boyama Reçetesi Tahmin Algoritmalarında Başarının Artırılmasına Yönelik Yeni Bir Yöntem, Doktora Tezi, Marmara Üniversitesi, Fen Bilimleri Enstitüsü, İstanbul.

2. Adeel, S., Ali, S., Bhatti, I. A. Zsila, F. (2009). Dyeing Of Cotton Fabric Using Pomegranate (Punica Granatum) Aqueous Extract. Asian J. Chem,. 21(5): 3493-3499.

3. Akgün, M., Alpay H., R., Becerir B. (2012). Kumaş Yapısal Parametreleri İle Reflektans değerleri Arasındaki İlişkilerin Değerlendirilmesi, Uludağ Üniversitesi Mühendislik-Mimarlık Fakültesi Dergisi, 17(1), 93-106.

4. Appolonia, L., Bruni, V., Cossu, R. and Vitulano, D. (2006). Computer-aided Monitoring of Buildings of Historical Importance Based on Color, Journal of Cultural Heritage, 7(2), 85-91.

5. Bebekli, M. (1998). Doğal Kaynaklardan Boyarmadde İzolesi Ve Pratikte Kullanılabilirliğinin İncelenmesi, Çukurova Üniversitesi, Fen Bilimleri Enstitüsü, Tekstil Mühendisliği Anabilim Dalı, Yüksek Lİsans Tezi, Adana.

6. Bostancı, Ş. (1987) Kağıt Hamuru Üretimi ve Ağartma Teknolojisi, Trabzon.

7. Calogero, G., Marco G. D. (2008). Red Sicilian Orange and Purple Egg Plant Fruits as Natural Sensitizers for Dye-sensitized Solar Cells, Solar Energy Materials \& Solar Cells, 92, 1341- 1346.

8. Çakar, P., (2012). Tezhipli El Yazması Eserlerde Bakır ve Diğer Elementlerin Pigmentler Üzerine Etkisinin İncelemesi, Yıldız Teknik Üniversitesi, Fen Bilimleri Enstitüsü, Kimya Mühendisliği Anabilim Dalı, Yüksek lisans Tezi, İstanbul.

9. Dixit, S., Jahan, S. (2005). Color fastness Properties of Euphorbia (Euphorbia Cotinifolia) Leaves Dye on Silk Fabric, Man-Made Textiles in Indian, 48(7) : 252-254.

10. Hunterlab, (1995). Colorimeters Versus Spectrophotometers, Hunter Lab Applications Note, 6 (5) p.1-2. 1996. CIE L*a*b* Color Scale, HunterLab Applications Note, 8 (7), p.1-4.

11. Kamel, M.M., El-Shishtawy, Reda, M., Yussef, B.M. Mashaly, H. (2005). Ultrasonic assisted dyeing: III. Dyeing of wool with lac as a natural dye Dye sand Pigments, 65(2), 103-110.

12. Korur, N.R. (1937). Planzenfarbstoffe in der Türkei, Ankara Yüksek Ziraat Enstitüsü, Ankara.

13. Krishnamurty, K.V., Siva, R. Senthil Kumar, T. (2002). Natural dye-yielding plants of Shervaroy Hills of Eastern Ghats. In Proceedings of National Seminar on the Conservation of the Eastern Ghats, Environment Protection Training and Research Institute, Hyderabad (pp. 151-153)..

14. Koparan, İ. (2015). Kızılçam (Pinus brutia Ten.) ve karaçam (Pinus nigra subsp. pallasiana) kabuklarının malalama elemanı olarak kullanım olanakları, Süleyman Demirel Üniversitesi / Fen Bilimleri Enstitüsü / Orman Mühendisliği Anabilim Dalı, Yüksek Lisans Tezi, Isparta 2015.

15. Kubelka, P. (1948). New contributions to the optics of intensely light-scattering materials part I, J. Opt. Soc. Am., 38(5), 448-457.

16. Luciana, G.A., Lusia, P., Paola, B., Alessandra, B. (1997). Rubiatinc torium a source of natural dyes: magronomic evaluation, quantitative analysis of alizarin and industri alassays, Industrial Cropsand Products, 6, 303-311.

17. Mc Donald, R. (1987). Colour Physics for Industry, SDC and Dyers Company Publications Trust, London.

18. Mc Laren, K. (1986). The Colour Science of Dyes and Pigments, Adam Hilger Ltd., ABD.

19. OGM, (2016). Oduna Dayalı Orman Ürünlerinin Üretim ve Pazarlama Faaliyetleri, Orman Genel Müdürlüğü İşletme ve Pazarlama Dairesi Başkanlığı, Ankara.

20. Onal, A. (1996). Extraction of Dyestuff from Madder Plant (Rubia tinctorum L.) and Dyeing of Wool, Feathered-Leather and Cotton. Tr. J. Chem., 20, 204-214.

21. Öğütgen, Z. (2008). Yıldız Teknik Üniversitesi Fen Bilimleri Enstitüsü Nar Kabuğu İle Farklı Mordanlar Kullanarak Yünlü Kumaş Boyama, FBE Kimya Anabilim Dalı, Anorganik Kimya Programı, Yüksek Lisans Tezi, İstanbul.

22. Öner, E. (2007). Optik Ağartma İşlemi Görmüş veya Fluoresans Boyarmaddeleri ile Boyanmış Tekstil Materyallerinde Renk Ölçümü, Tekstil Teknolojisi ve Kimyasındaki Son Gelişmeler Sempozyumu XI, s. 1628, Bursa.

23. Özcan, A. Zelzele, Ö. B. (2017). The Effect of Binder Type on the Physical Properties of Coated Paper. MSU J. of Sci., Volume 5, Issue 1, p 399-404. 
24. Özgür, M. Ü., Açıkgöz, Z. Ö., Sahinbaskan, B. Y., Gümrükçü, G. (2013). Woolen Fabric Dyeing with Punica granatum L. Rind by Using Different Mordants. Asian Journal of Chemistry, 25(4), 1956-1964.

25. Saha, P., Dutta, S. (2007). Production of Floral Dyes from Different Flowers Available in West Bengal for Textile and Dye Industry.

26. Tilley, R. (2000). Colour and Optical Properties of Materials: an Exploration of The Relationship Between Light. The Optical Properties of Materials and Colour, Chichester, J. Wiley \& Sons, England.

27. Yaman, K. (2012). Bitkisel Atıkların Değerlendirilmesi ve Ekonomik Önemi, Karabük Üniversitesi, İktisadi ve İdari Bilimler Fakültesi, 78050, Karabük, Kastamonu Üniversitesi, Orman Fakültesi Dergisi, 12 (2): 339 348. 